\title{
Association between demographics, socioeconomic status and metabolic syndrome in American adults: a cross-sectional study
}

Yang Liu

Second Xiangya Hospital

Liyan Jiang

University of South China

Mengru Zeng ( $\sim 148212084 @ c s u . e d u . c n$ )

Second Xiangya Hospital https://orcid.org/0000-0002-9735-8417

Research article

Keywords: Demographics, Socioeconomic status, Metabolic syndrome, National Health and Nutrition Examination Survey

Posted Date: November 25th, 2019

DOI: https://doi.org/10.21203/rs.2.17751/v1

License: (c) (1) This work is licensed under a Creative Commons Attribution 4.0 International License. Read Full License 


\section{Abstract}

Background Evidence regarding the association between demographics, socioeconomic status and metabolic syndrome is limited. We aim to investigate whether demographics and socioeconomic status are correlated with metabolic syndrome using data from National Health and Nutrition Examination Survey through $2013 / 2014$ to $2015 / 2016$.

Methods A total of 4313 selected participants were included in this cross-sectional study. The independent variables were demographics (age, gender,and race/ethnicity) and socioeconomic status (the ratio of family income to poverty). The dependent variable was metabolic syndrome. The covariates included data release cycle, education level, marital status, dietary data, health insurance, average alcoholic drinks, current smoking, sedentary activity hours, physical activity minutes, and body mass index. Logistic regression analysis was used to evaluate the association between demographics, socioeconomic status and metabolic syndrome.

Results In fully-adjusted models, we found that age was positively associated with metabolic syndrome (OR:1.05, 95\%Cl:1.04-1.05); compared with the male group, female was positively associated with metabolic syndrome in participants with body mass index under $25 \mathrm{~kg} / \mathrm{m} 2$ (OR:1.84, 95\%Cl:1.07-3.18) whereas it was negatively associated with metabolic syndrome in those with body mass index equal to or greater than $30 \mathrm{~kg} / \mathrm{m} 2$ (OR:0.62, 95\% Cl:0.48-0.81); compared with Mexican American, non-Hispanic Asian and other race/ethnicity were positively associated with metabolic syndrome in participants with body mass index under $25 \mathrm{~kg} / \mathrm{m} 2$ (OR: 7.30, 95\%Cl: 1.50-35.62 and OR: 6.09, 95\%Cl: 1.25-29.74, respectively) while non-Hispanic Black was negatively associated with metabolic syndrome in participants with body mass index equal to or greater than $25 \mathrm{~kg} / \mathrm{m} 2$ and less than $30 \mathrm{~kg} / \mathrm{m} 2$ (OR:0.58, 95\%Cl:0.36-0.92); there was no significant association between the ratio of family income to poverty and metabolic syndrome.

Conclusions Among the population of nationally representative non-pregnant American adults, there is a correlation between demographics and metabolic syndrome whereas no correlation between socioeconomic status and metabolic syndrome after multivariates adjustment. Healthcare interventions targeting those with metabolic syndrome including older individuals, obese males, along with females, non-Hispanic Asian and other race/ethnicity with BMI under $25 \mathrm{~kg} / \mathrm{m} 2$ are required to address these disparities.

\section{Background}

Metabolic syndrome (MS) is a pathophysiological state composed of abdominal obesity, raised blood pressure, dyslipidemia and elevated fasting glucose(1). Since MS has already become a global public health concern, understanding the impact of demographic factors and socioeconomic status on the prevalence of MS is of great significance. Endeavors toward these aspects will help to find the target population mostly needed for healthcare interventions against MS. However, there are few publications focusing on the association between demographics and MS. As for the association between socioeconomic status represented by the ratio of family income to poverty and MS, Loucks et al.(2) 
investigated it in participants from different age groups using data from the National Health and Nutrition Examination Survey (NHANES) through 1999/2000 to 2001/2002. Their findings indicated that, in females aged 25 to 65 years, the group of ratio of family income to poverty less than 1 was positively associated with MS compared with the group of ratio of family income to poverty greater than 3 after adjustment for age, race/ethnicity, and menopause. Yet, nonadjustment for body mass index (BMI) and other confounding variables may lead to unreliable conclusions. Thus, we perform this study to examine whether demographics (age, gender, and race/ethnicity) and socioeconomic status (the ratio of family income to poverty) are correlated with metabolic syndrome using data from NHANES through 2013/2014 to $2015 / 2016$.

\section{Methods}

\section{Study design, setting, and participants}

NHANES, the data source, has become a series of continuous national cross-sectional surveys conducted every two years by the National Center for Health Statistics (NCHS). The NHANES program selected a representative sample of the civilian, non-institutionalized US population using a complex, stratified, multistage probability sampling design(3). Sampling weights were employed to obtain U.S. nationally representative estimates and calculations accounted for the complex survey design, survey non-response, and post-stratification of the program.

We collected data from NHANES during 2 two-year cycles from 2013/2014 to 2015/2016. Adults aged 20 years old or older who fasted for at least 8 hours and had complete information on waist circumference, blood pressure, triglyceride, high-density lipoprotein (HDL) cholesterol, and fasting glucose were included. Meanwhile, females who had positive lab pregnancy test results or were self-reported pregnant at examination were excluded. The final analytic sample size was 4313. Detailed procedures of participants selection were shown in Fig. 1.

\section{Variables}

Continuous variables consisted of age (year), dietary data, and BMI $\left(\mathrm{kg} / \mathrm{m}^{2}\right)$. Adults who aged 80 years or above were assigned a value of 80 years. Daily dietary data included energy intake (kcal), protein intake (gm), carbohydrate intake (gm), total sugars intake (gm), dietary fiber intake (gm), and total fat intake (gm).

Categorical variables were stated as follows. Data release cycle was documented as 2013/2014 or 2015/2016. Gender included two identities, male and female. Race/ethnicity was determined by self- or parent-reported survey responses, coded as Mexican American, non-Hispanic White, non-Hispanic Black, Non-Hispanic Asian, and other race/ethnicity. Education level was divided into three groups, which included high school graduate/General Educational Development (GED) or equivalent or below, some college or Associate of Arts (AA) degree, and college graduate or above. Marital status was classified into 
two groups, married or living with partner (i.e., non-single state) and widowed or divorced or separated or never married (i.e., single state). The ratio of family income to poverty was categorized into three groups $(<1, \geq 1$ and $<3$, and $\geq 3)$. Health insurance was divided into two groups, being covered by health insurance and not being covered by health insurance. Alcohol and current cigarette use were also categorized into two ( $<3$ and $\geq 3$ drinks per day) and three groups (every day, some days, and not at all), respectively. Sedentary activity time was classified into four groups $(<4, \geq 4$ and $<6, \geq 6$ and $<8$, and $\geq 8$ hours per day)(4). Total work time was divided into four groups $(0,>0$ and $<150, \geq 150$ and $\leq 300$, and $>$ 300 minutes per week), which was also applied to total recreational activity time(4).

\section{Identification of metabolic syndrome}

As the dependent variable, MS was determined by criteria published in 2009 (Table S1) $(5,6)$. Participants with any 3 of 5 risk factors were diagnosed as MS. Waist circumference was measured at the high point of the iliac crest to the nearest $0.1 \mathrm{~cm}$ at minimal respiration. The average of all available blood pressure readings collected in the mobile examination center was adopted. Participants currently taking prescribed medicine for high blood pressure were counted as participants with elevated blood pressure. Levels of triglycerides and HDL cholesterol were measured using enzymatic assays and immunoassays, respectively. According to the International Classification of Diseases, Tenth Revision, Clinical Modification (ICD-10-CM) code description of prescription medications, participants currently taking prescribed medicine for pure hyperglyceridemia were counted as participants with elevated triglyceride. Likewise, participants currently taking prescribed medicine for pure low HDL cholesterol, if any, were counted as participants with reduced HDL cholesterol. Fasting glucose concentrations were determined using an enzymatic reaction. Participants currently taking diabetic pills or insulin to lower blood sugar were counted as participants with elevated glucose.

\section{Statistical analysis}

Statistical analysis was performed according to the guidelines of Centers for Disease Control and Prevention (CDC) (https://wwwn.cdc.gov/nchs/nhanes/tutorials/default.aspx). Continuous variables were represented as mean \pm standard deviation, while categorical variables were represented as percentages. Weighted linear regression models were used to calculate the differences in continuous variables among different groups of independent variables (age, gender, race/ethnicity, and the ratio of family income to poverty), while weighted chi-square tests were used to calculate the differences in categorical variables among different groups of those dependent variables.

Univariate and multivariate linear regression models were employed to investigate whether demographics and socioeconomic status are associated with MS in selected participants. We constructed four models: crude model with no adjusted covariates; model 1 with adjusted demographic covariates; model 2 with adjusted covariates in model 1 plus data release cycle, education level, marital status, the ratio of family income to poverty (except for it being the independent variable), energy intake, protein intake, carbohydrate intake, total sugars intake, dietary fiber intake, total fat intake, health insurance, average alcoholic drinks, current smoking, sedentary activity hours, total work activity minutes, and total recreational activity minutes; model 3 with adjusted covariates in model 2 plus BMI. For an ordered 
categorical variable being the dependent variable, $\mathrm{P}$ for trend was calculated. For missing of categorical covariates, we set these missing values as groups to be adjusted in the models.

Subgroup analyses based on BMI were performed using stratified linear regression models. For BMI, we firstly converted it to a categorical variable according to clinical cut points and then test interaction effects between dependent variables and BMI by the log likelihood ratio test.

Multiple imputation for missing of variables and further analyses were performed to ensure the robustness of our results. Five datasets with multivariate imputation were created by chained equations package(7). We repeated all correlation analyses and subgroup analyses using the imputed datasets and then combined the results by Rubin's rules.

All analyses were performed with the statistical software package R-3.4.3 (http://www.R-project.org, The R Foundation) and Empower-Stats (http://www.empowerstats.com, X\&Y Solutions,Inc., Boston, MA). A P value less than 0.05 (two-sided) was considered statistically significant. A $P_{\text {interaction }}$ value less than 0.10 (two-sided) was considered statistically significant.

\section{Results}

\section{Age and metabolic syndrome}

The weighted distribution of characteristics of selected population by age groups was shown in Table S2. Among three groups, the distribution of gender, education level, and dietary fiber intake was similar. Compared with the youngest age group (age $\geq 20$ and $<40$ years), participants in older age groups had higher proportions of 2015-2016 cycle, non-Hispanic White, non-single state, the ratio of family income to poverty equal to or greater than 3 , being covered by health insurance, average alcoholic drinks less than 3 , no current smoking, sedentary activity hours equal to or greater than 4 , no work activity, no recreational activity, elevated waist circumference, elevated blood pressure, elevated triglyceride, and elevated fasting glucose. Besides, they had higher average BMI. On the contrary, they had less average energy, protein, carbohydrate, total sugars, and total fat intakes.

The correlation analysis between age and MS was presented in Table 1. Crude model is an unadjusted model. This model indicated that age was positively associated with MS (odds ratio (OR):1.04, 95\%confidence interval (CI):1.03-1.04). In model 1, after adjusting for gender and race/ethnicity, the positive correlation between age and MS remained stable (OR:1.04, 95\%Cl:1.03-1.04). Similar results can be obtained in model 2 (OR:1.04, 95\%Cl:1.03-1.04) and model 3 (OR:1.05, 95\%Cl:1.04-1.05). We also grouped age by tertile and calculated $\mathrm{P}$ for trend. The results corroborated those of age as a continuous variable. All results were verified using multiply-imputed datasets (Table S3). 
Table 1

Association between age and metabolic syndrome in different models

\begin{tabular}{|c|c|c|c|c|c|c|c|c|}
\hline & \multicolumn{2}{|c|}{$\begin{array}{l}\text { Crude model } \\
(\mathrm{N}=4313)\end{array}$} & \multicolumn{2}{|l|}{$\begin{array}{l}\text { Model } 1 \\
(N=4313)\end{array}$} & \multicolumn{2}{|l|}{$\begin{array}{l}\text { Model } 2 \\
(\mathrm{~N}=4100)\end{array}$} & \multicolumn{2}{|c|}{$\begin{array}{l}\text { Model } 3 \\
(N=4091)\end{array}$} \\
\hline & $\begin{array}{l}\text { OR } \\
(95 \% \mathrm{Cl})\end{array}$ & $\begin{array}{l}P \\
\text { value }\end{array}$ & $\begin{array}{l}\text { OR } \\
(95 \% \mathrm{Cl})\end{array}$ & $\begin{array}{l}P \\
\text { value }\end{array}$ & $\begin{array}{l}\text { OR } \\
(95 \% \mathrm{Cl})\end{array}$ & $\begin{array}{l}P \\
\text { value }\end{array}$ & $\begin{array}{l}\text { OR } \\
(95 \% \mathrm{Cl})\end{array}$ & $\begin{array}{l}P \\
\text { value }\end{array}$ \\
\hline $\begin{array}{l}\text { Age } \\
\text { (year) }\end{array}$ & $\begin{array}{l}1.04 \\
(1.03- \\
1.04)\end{array}$ & $<.01 *$ & $\begin{array}{l}1.04 \\
(1.03- \\
1.04)\end{array}$ & $<$ & $\begin{array}{l}1.04 \\
(1.03- \\
1.04)\end{array}$ & $<.01 *$ & $\begin{array}{l}1.05 \\
(1.04- \\
1.05)\end{array}$ & <.01* \\
\hline \multicolumn{9}{|l|}{$\begin{array}{l}\text { Age } \\
\text { groups } \\
\text { (year) }\end{array}$} \\
\hline$\geq 20,<40$ & \multicolumn{2}{|l|}{ Reference } & \multicolumn{2}{|l|}{ Reference } & \multicolumn{2}{|l|}{ Reference } & \multicolumn{2}{|l|}{ Reference } \\
\hline$\geq 40,<60$ & $\begin{array}{l}2.57 \\
(2.18- \\
3.04)\end{array}$ & $<.01 *$ & $\begin{array}{l}2.57 \\
(2.18- \\
3.04)\end{array}$ & $<.01 *$ & $\begin{array}{l}2.40 \\
(2.01- \\
2.88)\end{array}$ & $<.01 *$ & $\begin{array}{l}2.57 \\
(2.09- \\
3.16)\end{array}$ & $<.01 *$ \\
\hline$\geq 60$ & $\begin{array}{l}4.61 \\
(3.90- \\
5.45)\end{array}$ & $<.01 *$ & $\begin{array}{l}4.53 \\
(3.83- \\
5.35)\end{array}$ & $<.01 *$ & $\begin{array}{l}3.87 \\
(3.17- \\
4.71)\end{array}$ & $<.01 *$ & $\begin{array}{l}5.79 \\
(4.59- \\
7.29)\end{array}$ & $<.01 *$ \\
\hline$P$ for trend & & ${ }_{0.01 *}$ & & ${ }_{0.01 *}$ & & $\begin{array}{l}<.01 * \\
0 .\end{array}$ & & $\begin{array}{l}<.01^{*} \\
\end{array}$ \\
\hline \multicolumn{9}{|c|}{ OR: odds ratio; Cl: confidence interval. } \\
\hline \multicolumn{9}{|c|}{ Crude model adjust for none. } \\
\hline \multicolumn{9}{|c|}{ Model 1 adjust for gender and race/ethnicity. } \\
\hline \multicolumn{9}{|c|}{$\begin{array}{l}\text { Model } 2 \text { adjust for all adjusted covariates in model } 1 \text { plus data release cycle, education level, marital } \\
\text { status, the ratio of family income to poverty, energy intake, protein intake, carbohydrate intake, total } \\
\text { sugars intake, dietary fiber intake, total fat intake, health insurance, average alcoholic drinks, current } \\
\text { smoking, sedentary activity hours, total work activity minutes, and total recreational activity minutes. }\end{array}$} \\
\hline \multicolumn{9}{|c|}{ Model 3 adjust for all adjusted covariates in model 2 plus body mass index. } \\
\hline * $P$ value $<c$ & & & & & & & & \\
\hline
\end{tabular}

\section{Gender and metabolic syndrome}

The weighted distribution of characteristics of selected participants by gender was shown in Table S4. Between two groups, the distribution of percentages of data release cycle, race/ethnicity, sedentary activity hours, and elevated blood pressure was similar. Compared with their male counterparts, females had higher proportions of high school graduate above, the ratio of family income to poverty less than 1 , being covered by health insurance, average alcoholic drinks less than 3 , total work activity minutes equal to 0 , total recreational activity minutes equal to or greater than 0 and less than 150 , elevated waist 
circumference, and reduced HDL cholesterol. Besides, they had higher average age and BMI. In contrast, they had lower proportions of non-single state, no current smoking, elevated triglyceride, and elevated fasting glucose. They also had less average energy, protein, carbohydrate, total sugars, dietary fiber, and total fat intakes.

The correlation analysis between gender and MS was presented in Table 2. In all four models, compared with the male group, there was no significant correlation between female and MS. However, we found that the effect size of OR in the female group changed from 1.13 in model 2 to 0.88 in model 3 after further adjusting for BMI. To investigate whether there is any interaction between gender and BMI for metabolic syndrome, an interaction test was performed. We found an interaction between gender and BMI for MS(Table S5). After that, a subgroup analysis by BMI was undertaken. The results demonstrated that, compared with the male group, female was positively associated with MS in participants with BMI less than $25 \mathrm{~kg} / \mathrm{m}^{2}$ (OR:1.84, 95\%Cl:1.07-3.18) whereas it was negatively associated with MS in those with BMl equal to or greater than $30 \mathrm{~kg} / \mathrm{m}^{2}$ (i.e., obesity) (OR:0.62, 95\%Cl:0.48-0.81) (Table 3). The results of correlation analysis were confirmed by those from multiply-imputed datasets (Tables S6). The subgroup analysis by BMI using multiply-imputed datasets also showed similar results(Table S7).

Table 2

Association between gender and metabolic syndrome in different models

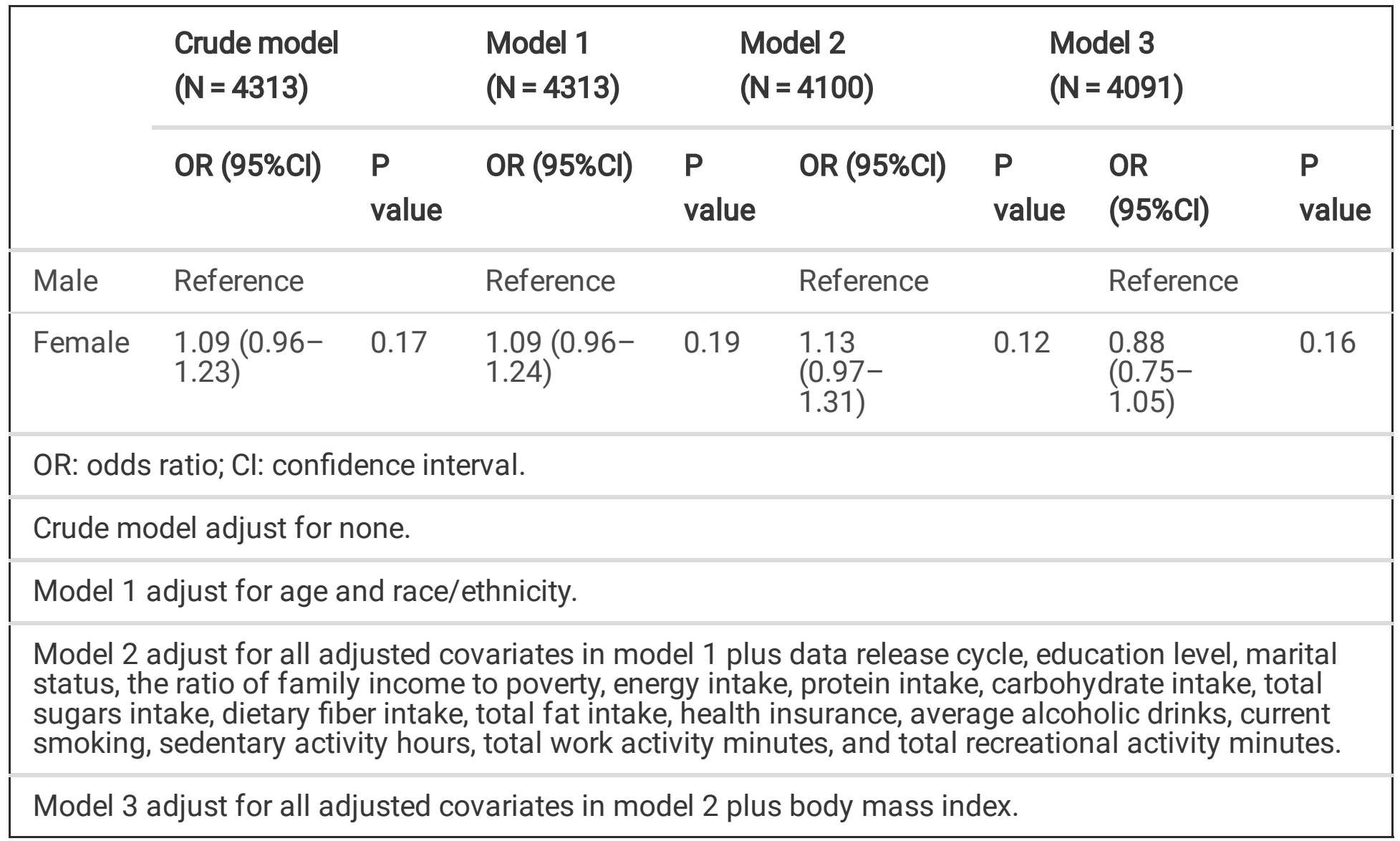


Table 3

Association between gender and metabolic syndrome in BMI groups

\begin{tabular}{|c|c|c|c|c|c|c|}
\hline & \multicolumn{2}{|c|}{$\mathrm{BMI}<25 \mathrm{~kg} / \mathrm{m}^{2}(\mathrm{~N}=1156)$} & \multicolumn{2}{|c|}{$\begin{array}{l}\mathrm{BMI} \geq 25,<30 \mathrm{~kg} / \mathrm{m}^{2}(\mathrm{~N}= \\
1329)\end{array}$} & \multicolumn{2}{|c|}{$\mathrm{BMI} \geq 30 \mathrm{~kg} / \mathrm{m}^{2}(\mathrm{~N}=1606)$} \\
\hline & OR $(95 \% \mathrm{Cl})$ & $\begin{array}{l}P \\
\text { value }\end{array}$ & OR $(95 \% \mathrm{Cl})$ & $P$ value & OR $(95 \% \mathrm{Cl})$ & $P$ value \\
\hline Male & Reference & & Reference & & Reference & \\
\hline Female & $\begin{array}{l}1.84(1.07- \\
3.18)\end{array}$ & $0.03^{\star}$ & $1.28(0.96-1.71)$ & 0.10 & $\begin{array}{l}0.62(0.48- \\
0.81)\end{array}$ & $<0.01 *$ \\
\hline \multicolumn{7}{|c|}{ BMI:body mass index; OR: odds ratio; $\mathrm{Cl}$ : confidence interval. } \\
\hline \multicolumn{7}{|c|}{$\begin{array}{l}\text { Adjusted for age, race/ethnicity, data release cycle, education level, marital status, the ratio of family } \\
\text { income to poverty, energy intake, protein intake, carbohydrate intake, total sugars intake, dietary fiber } \\
\text { intake, total fat intake, health insurance, average alcoholic drinks, current smoking, sedentary activity } \\
\text { hours, total work activity minutes, total recreational activity minutes, and body mass index. }\end{array}$} \\
\hline \multicolumn{7}{|c|}{ * $P$ value $<0.05$} \\
\hline
\end{tabular}

\section{Race/ethnicity and metabolic syndrome}

The weighted distribution of characteristics of selected population by race/ethnicity was shown in Table S8. Among five groups, the distribution of percentages of data release cycle and gender was similar. Compared with other groups, Mexican American had the highest proportions of high school graduate/GED or equivalent or below, the ratio of family income to poverty less than 1, average alcoholic drinks equal to or greater than 3 , sedentary activity hours less than 4 , total recreational activity minutes equal to 0 , elevated waist circumference, elevated triglyceride, reduced HDL cholesterol, and elevated fasting glucose. Non-Hispanic White had the highest proportion of no current smoking. Besides, they had the highest average energy, protein, carbohydrate, total sugars, dietary fiber, and total fat intakes. In contrast, they had the lowest proportion of being covered by health insurance and average age. Non-Hispanic Black had the highest proportion of elevated blood pressure and average BMI. Non-Hispanic Asian had the highest proportions of non-single state and total work activity minutes equal to 0 .

The correlation analysis between race/ethnicity and MS was presented in Table 4. In the crude model, compared with Mexican American, non-Hispanic Asian had a negative correlation with MS (OR:0.40, 95\% Cl:0.31-0.51). Similar results can be seen in model 1 and 2. Besides, in model 1 and 2, non-Hispanic White had a negative correlation with MS (OR: $0.78,95 \% \mathrm{Cl}: 0.64-0.94$ and OR: $0.80,95 \% \mathrm{Cl}: 0.64-0.99$, respectively). Moreover, in model 1 and 3, non-Hispanic Black had a negative correlation with MS (OR: 0.77, 95\%Cl: $0.62-0.96$ and OR: $0.72,95 \% \mathrm{Cl}$ : $0.55-0.95$, respectively). Of note, the effect size of OR in non-Hispanic Asian changed from 0.44 in model 2 to 1.15 in model 3 after further adjusting for BMI. To investigate whether there is any interaction between race/ethnicity and BMI for MS, an interaction test was carried out. We found an interaction between race/ethnicity and BMI for MS (Table S9). Then, a subgroup 
analysis by BMI was performed. The results indicated that, compared with Mexican American, nonHispanic Asian and other race/ethnicity were positively associated with MS in participants with BMI less than $25 \mathrm{~kg} / \mathrm{m}^{2}$ (OR: $10.09,95 \% \mathrm{Cl}: 1.97-51.59$ and OR: 6.79, 95\% Cl: 1.33-34.68, respectively) whereas non-Hispanic Black was negatively associated with MS in those with BMI equal to or greater than $25 \mathrm{~kg} / \mathrm{m}^{2}$ and less than $30 \mathrm{~kg} / \mathrm{m}^{2}$ (i.e.,overweight) (OR: 0.56, 95\%Cl: 0.35-0.89) (Table 5). However, the results of correlation analysis using multiply-imputed datasets demonstrated that, in model 2, there was no significant correlation between non-Hispanic White and MS when compared with Mexican American(Table S10). The results of subgroup analysis by BMI were generally supported by those from multiply-imputed datasets (Tables S11). 
Table 4

Association between race/ethnicity and metabolic syndrome in different models

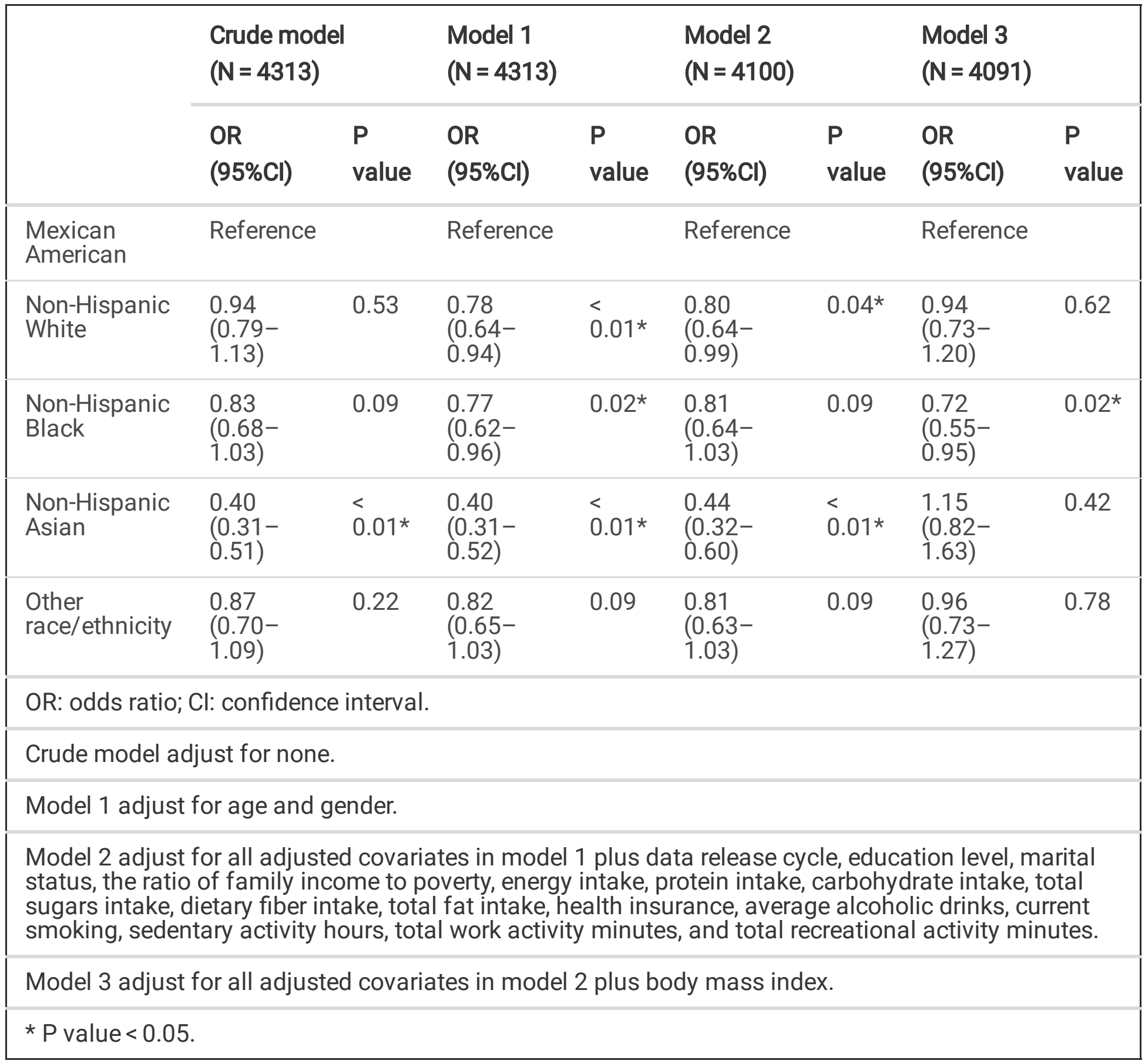


Table 5

Association between race/ethnicity and metabolic syndrome in BMI groups

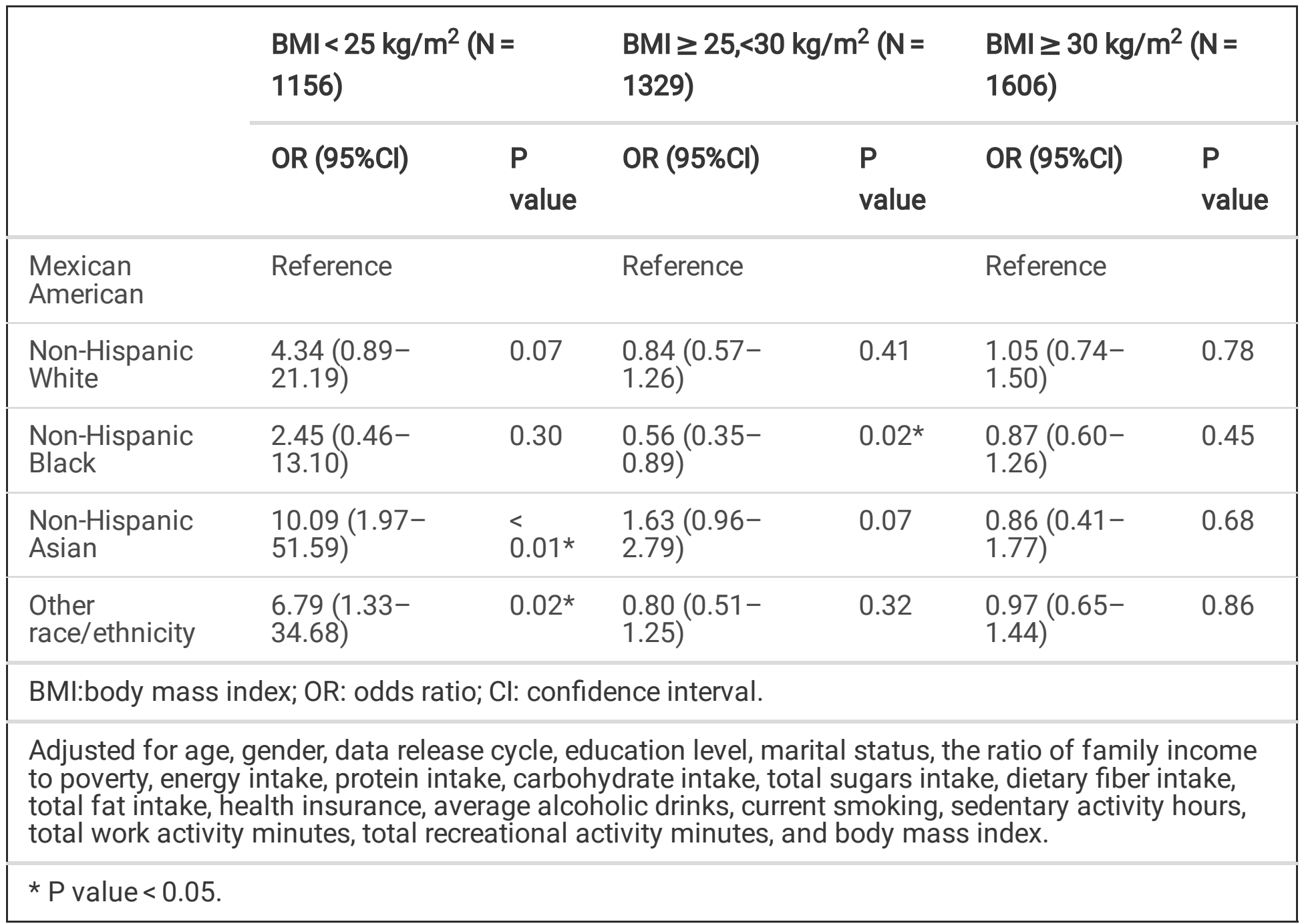

\section{The ratio of family income to poverty and metabolic syndrome}

The weighted distribution of characteristics of selected participants by the ratio of family income to poverty was shown in Table S12. Among three groups, the distribution of percentages of elevated waist circumference, blood pressure, triglyceride, and fasting glucose along with energy intake was similar. Compared with the lowest ratio of family income to poverty group (the ratio of family income to poverty < 1), participants with higher ratio of family income to poverty had higher proportions of 2015-2016 cycle, males, non-Hispanic White, college graduate or above, non-single state, being covered by health insurance, average alcoholic drinks less than 3 , no current smoking, sedentary activity hours equal to or greater than 6 , total work activity minutes greater than 0 and equal to or less than 300 , total recreational activity minutes greater than 0 . Besides, they had higher average age, protein intake, dietary fiber intake. In contrast, they had a lower proportion of reduced HDL cholesterol as well as less average carbohydrate intake, total sugars intake, total fat intake, and BMI. 
The correlation analysis between the ratio of family income to poverty and MS was presented in Table 6 . The unadjusted crude model demonstrated that, compared with the group of ratio of family income to poverty less than 1, the group of ratio of family income to poverty equal to or greater than 3 was inversely associated with MS (OR:0.78, 95\% Cl:0.66-0.93). In model 1, after adjusting for demographic variables, this inverse correlation between the ratio of family income to poverty and MS remained stable (OR:0.71, $95 \% \mathrm{Cl}: 0.59-0.86)$. However, in model 2 and 3 , no significant inverse correlation between them was detected. The results in crude model, model 1 and 3 were ascertained by those from multiply-imputed datasets (Table S13). Nonetheless, the results in model 2 using multiply-imputed datasets indicated that there was an inverse correlation between the ratio of family income to poverty and MS (OR:0.78, 95\% Cl:0.63-0.98) (Tables S13). 
Table 6

Association between the ratio of family income to poverty and metabolic syndrome in different models

\begin{tabular}{|c|c|c|c|c|c|c|c|c|}
\hline & \multicolumn{2}{|c|}{$\begin{array}{l}\text { Crude model } \\
(\mathrm{N}=3972)\end{array}$} & \multicolumn{2}{|l|}{$\begin{array}{l}\text { Model } 1 \\
(\mathrm{~N}=3972)\end{array}$} & \multicolumn{2}{|l|}{$\begin{array}{l}\text { Model } 2 \\
(\mathrm{~N}=3793)\end{array}$} & \multicolumn{2}{|l|}{$\begin{array}{l}\text { Model } 3 \\
(\mathrm{~N}=3785)\end{array}$} \\
\hline & $\begin{array}{l}\text { OR } \\
(95 \% \mathrm{Cl})\end{array}$ & $\begin{array}{l}P \\
\text { value }\end{array}$ & $\begin{array}{l}\text { OR } \\
(95 \% \mathrm{Cl})\end{array}$ & $\begin{array}{l}P \\
\text { value }\end{array}$ & $\begin{array}{l}\text { OR } \\
(95 \% \mathrm{Cl})\end{array}$ & $\begin{array}{l}P \\
\text { value }\end{array}$ & $\begin{array}{l}\text { OR } \\
(95 \% \mathrm{Cl})\end{array}$ & $\begin{array}{l}P \\
\text { value }\end{array}$ \\
\hline $\begin{array}{l}\text { The ratio of } \\
\text { family } \\
\text { income to } \\
\text { poverty }<1\end{array}$ & \multicolumn{2}{|l|}{ Reference } & \multicolumn{2}{|l|}{ Reference } & \multicolumn{2}{|l|}{ Reference } & \multicolumn{2}{|l|}{ Reference } \\
\hline $\begin{array}{l}\text { The ratio of } \\
\text { family } \\
\text { income to } \\
\text { poverty } \geq 1 \\
<3\end{array}$ & $\begin{array}{l}1.02 \\
(0.86- \\
1.20)\end{array}$ & 0.82 & $\begin{array}{l}0.91 \\
(0.76- \\
1.09)\end{array}$ & 0.30 & $\begin{array}{l}0.93 \\
(0.77- \\
1.13)\end{array}$ & 0.47 & $\begin{array}{l}0.96 \\
(0.78- \\
1.20)\end{array}$ & 0.74 \\
\hline $\begin{array}{l}\text { The ratio of } \\
\text { family } \\
\text { income to } \\
\text { poverty } \geq 3\end{array}$ & $\begin{array}{l}0.78 \\
(0.66- \\
0.93)\end{array}$ & $<.01 *$ & $\begin{array}{l}0.71 \\
(0.59- \\
0.86)\end{array}$ & $<.01 *$ & $\begin{array}{l}0.82 \\
(0.65- \\
1.02)\end{array}$ & 0.08 & $\begin{array}{l}0.93 \\
(0.72- \\
1.19)\end{array}$ & 0.56 \\
\hline \multicolumn{2}{|l|}{$P$ for trend } & ${ }_{0.01 *}$ & & \multicolumn{2}{|l|}{$<.01 *$} & \multicolumn{2}{|l|}{0.07} & 0.56 \\
\hline \multicolumn{9}{|c|}{ OR: odds ratio; Cl: confidence interval. } \\
\hline \multicolumn{9}{|c|}{ Crude model adjust for none. } \\
\hline \multicolumn{9}{|c|}{ Model 1 adjust for age, gender, and race/ethnicity. } \\
\hline \multicolumn{9}{|c|}{$\begin{array}{l}\text { Model } 2 \text { adjust for all adjusted covariates in model } 1 \text { plus data release cycle, education level, marital } \\
\text { status, energy intake, protein intake, carbohydrate intake, total sugars intake, dietary fiber intake, total } \\
\text { fat intake, health insurance, average alcoholic drinks, current smoking, sedentary activity hours, total } \\
\text { work activity minutes, and total recreational activity minutes. }\end{array}$} \\
\hline \multicolumn{9}{|c|}{ Model 3 adjust for all adjusted covariates in model 2 plus body mass index. } \\
\hline * $P$ value $<0$ & & & & & & & & \\
\hline
\end{tabular}

\section{Discussion}

The objective of our study is to examine whether demographics and socioeconomic status are independently associated with MS. Overall, we conclude that, among the population of nationally representative non-pregnant American adults, there is a correlation between demographics and MS whereas no correlation between socioeconomic status and MS after multivariates adjustment.

The study indicated that age was positively associated with MS. Aguilar et al.(8) reported that the prevalence of MS increased with the increase of age in the United States using the data from NHANES 
through 2003 to 2012. We confirmed that there was a positive correlation between age and MS via multivariate logistic regression analyses. Besides, we also converted age into a categorical variable by tertile and calculated $\mathrm{P}$ for trend. The purpose was to verify the results of age as a continuous variable and to observe the possibility of a nonlinear relationship between age and MS. Our study demonstrated that there was no nonlinear relationship between them. The positive association between age and MS might be attributed to metabolic changes during aging and the accumulation of risk factors $(9,10)$.

The study revealed that, compared with the male group, female was positively associated with MS in participants with BMI under $25 \mathrm{~kg} / \mathrm{m}^{2}$ whereas it was inversely associated with MS in obese participants. In participants with BMI under $25 \mathrm{~kg} / \mathrm{m}^{2}$, males were protected against MS compared with their female counterparts. This might be related to a higher testosterone level in males with BMI under $25 \mathrm{~kg} / \mathrm{m}^{2}$. A randomized controlled trial conducted by Emmelot-Vonk et al.(11) indicated that exogenous testosterone had a beneficial impact on lean body mass and insulin sensitivity in older men with a low-normal testosterone level. Our results also suggested a gender difference in obesity-related complications like MS. Pettersson et al.(12) reported that while there was low-grade systemic inflammation in obese male mice induced by high-fat diet, there was none in obese female mice. Underlying mechanisms behind protection against metabolic diseases in obese females are not well understood yet. The discrepancy in relationship of gender and MS among different BMI groups might be ascribed to a protective role of estrogen in metabolic diseases in females as well as a obesity-related low testosterone concentration in males(13, 14).

The study demonstrated that compared with Mexican American, non-Hispanic Asian and other race/ethnicity were positively associated with MS in participants with BMI under $25 \mathrm{~kg} / \mathrm{m}^{2}$ while nonHispanic Black was inversely associated with MS in overweight participants. Palaniappan et al.(15) reported that Asian American had a higher prevalence of MS even with lower BMI than non-Hispanic White using electronic health records of 43507 primary care patients aged 35 years or older in the San Francisco Bay Area. Together, these results suggest there is an ethnic difference in the prevalence of MS.

The study showed that there was no significant correlation between socioeconomic status and MS. As a widely used indicator of socioeconomic status, the ratio of family income to poverty is calculated as the ratio of the midpoint of the family income category to the family's appropriate poverty threshold set by the United States Census Bureau (USCB) specific to the calendar year(16). A prior study performed by Loucks et al.(2) demonstrated that, compared with the group of ratio of family income to poverty greater than 3 , the group of ratio of family income to poverty less than 1 was positively associated with MS in females aged 25 to 65 years. Compared with their study, our study has made more adequate adjustments to reveal the real relationship between socioeconomic status and MS. This inconsistency might lie in nonadjustment for BMI and other confounding variables in their study.

Several limitations are noticeable. Firstly, owing to the nature of cross-sectional study, our study cannot provide evidence on the causal relationship between demographics, socioeconomic status and MS. Secondly, we exclude pregnant females in view of many metabolic alterations in pregnancy(17). 
Therefore, the results cannot be used in this population. Thirdly, since we use existed data from NHANES, there might be some unmeasurable confounding factors. Although we have tried to make more adequate adjustments than previous researchers. Despite these limitations, our study has its strengths. Firstly, multiple imputation for missing of variables and further analyses are performed to ensure the robustness of our findings. Secondly, the use of nationally representative data from NHANES enables us to generate generalizable results to entire non-pregnant American adults with MS.

\section{Conclusions}

Among the population of nationally representative non-pregnant American adults, there is a correlation between demographics and metabolic syndrome whereas no correlation between socioeconomic status and metabolic syndrome after multivariates adjustment. Healthcare interventions targeting those with metabolic syndrome including older individuals, obese males, along with females, non-Hispanic Asian and other race/ethnicity with BMI under $25 \mathrm{~kg} / \mathrm{m}^{2}$ are required to address these disparities.

\section{Abbreviations}

AA:Associate of Arts; BMl:body mass index; CDC:Centers for Disease Control and Prevention; Cl:confidence interval; GED:General Educational Development; HDL:high-density lipoprotein; ICD-10CM:International Classification of Diseases, Tenth Revision, Clinical Modification; MS:Metabolic syndrome; NCHS:National Center for Health Statistics; NHANES:National Health and Nutrition Examination Survey; OR:odds ratio; USCB:United States Census Bureau.

\section{Declarations}

Acknowledgements

None.

\section{Authors' contributions}

$M Z$ designed the study. MZ, YL and LJ collected, analysed, and interpreted the data. YL drafted the manuscript. LJ prepared the tables and supplementary information. MZ reviewed the manuscript. All authors read and approved the final manuscript.

\section{Funding}

The authors received no specific funding for this work. 
Availability of data and materials

The datasets supporting the conclusions of this article are available in NHANES, https://wwwn.cdc.gov/nchs/nhanes/Default.aspx.

Ethics approval and consent to participate

NHANES was approved by the National Center for Health Statistics Institutional/Ethics Review Board and all participants provided written informed consent. Given it was an analysis of existed anonymous data and did not involve human participants, the Central South University Institutional Review Board waived the need for reviewing the study.

Consent for publication

Not applicable.

Competing interests

The authors declare that they have no competing interests.

\section{References}

1. Sperling LS, Mechanick JI, Neeland IJ, Herrick CJ, Despres JP, Ndumele CE, et al. The CardioMetabolic Health Alliance: Working Toward a New Care Model for the Metabolic Syndrome. Journal of the American College of Cardiology. 2015;66(9):1050-67.

2. Loucks EB, Magnusson KT, Cook S, Rehkopf DH, Ford ES, Berkman LF. Socioeconomic position and the metabolic syndrome in early, middle, and late life: evidence from NHANES 1999-2002. Ann Epidemiol. 2007;17(10):782-90.

3. Chen TC, Parker JD, Clark J, Shin HC, Rammon JR, Burt VL. National Health and Nutrition Examination Survey: Estimation Procedures, 2011-2014. Vital Health Stat 2. 2018(177):1-26.

4. Ussery EN, Fulton JE, Galuska DA, Katzmarzyk PT, Carlson SA. Joint Prevalence of Sitting Time and Leisure-Time Physical Activity Among US Adults, 2015-2016. Jama. 2018;320(19):2036-8.

5. Alberti KG, Eckel RH, Grundy SM, Zimmet PZ, Cleeman JI, Donato KA, et al. Harmonizing the metabolic syndrome: a joint interim statement of the International Diabetes Federation Task Force on Epidemiology and Prevention; National Heart, Lung, and Blood Institute; American Heart Association; World Heart Federation; International Atherosclerosis Society; and International Association for the Study of Obesity. Circulation. 2009;120(16):1640-5. 
6. Expert Panel on Detection E, Treatment of High Blood Cholesterol in A. Executive Summary of The Third Report of The National Cholesterol Education Program (NCEP) Expert Panel on Detection, Evaluation, And Treatment of High Blood Cholesterol In Adults (Adult Treatment Panel III). Jama. $2001 ; 285(19): 2486-97$.

7. van Buuren S, Groothuis-Oudshoorn K. mice: Multivariate Imputation by Chained Equations in R. 2011. 2011;45(3):67.

8. Aguilar M, Bhuket T, Torres S, Liu B, Wong RJ. Prevalence of the metabolic syndrome in the United States, 2003-2012. Jama. 2015;313(19):1973-4.

9. Razzouk L, Muntner P. Ethnic, gender, and age-related differences in patients with the metabolic syndrome. Curr Hypertens Rep. 2009;11(2):127-32.

10. Tigno XT, Gerzanich G, Hansen BC. Age-related changes in metabolic parameters of nonhuman primates. The journals of gerontology Series A, Biological sciences and medical sciences. 2004;59(11):1081-8.

11. Emmelot-Vonk MH, Verhaar HJ, Nakhai Pour HR, Aleman A, Lock TM, Bosch JL, et al. Effect of testosterone supplementation on functional mobility, cognition, and other parameters in older men: a randomized controlled trial. Jama. 2008;299(1):39-52.

12. Pettersson US, Walden TB, Carlsson PO, Jansson L, Phillipson M. Female mice are protected against high-fat diet induced metabolic syndrome and increase the regulatory $\mathrm{T}$ cell population in adipose tissue. PLoS One. 2012;7(9):e46057.

13. Liu S, Mauvais-Jarvis F. Minireview: Estrogenic protection of beta-cell failure in metabolic diseases. Endocrinology. 2010;151(3):859-64.

14. Wang C, Jackson G, Jones TH, Matsumoto AM, Nehra A, Perelman MA, et al. Low testosterone associated with obesity and the metabolic syndrome contributes to sexual dysfunction and cardiovascular disease risk in men with type 2 diabetes. Diabetes care. 2011;34(7):1669-75.

15. Palaniappan LP, Wong EC, Shin JJ, Fortmann SP, Lauderdale DS. Asian Americans have greater prevalence of metabolic syndrome despite lower body mass index. Int J Obes (Lond). 2011;35(3):393400.

16. Lee JA, Johns TS, Melamed ML, Tellechea L, Laudano M, Stern JM, et al. Associations Between Socioeconomic Status and Urge Urinary Incontinence: An Analysis of NHANES 2005-2016. J Urol. 2019:101097JU0000000000000542.

17. Lain KY, Catalano PM. Metabolic changes in pregnancy. Clin Obstet Gynecol. 2007;50(4):938-48.

\section{Figures}




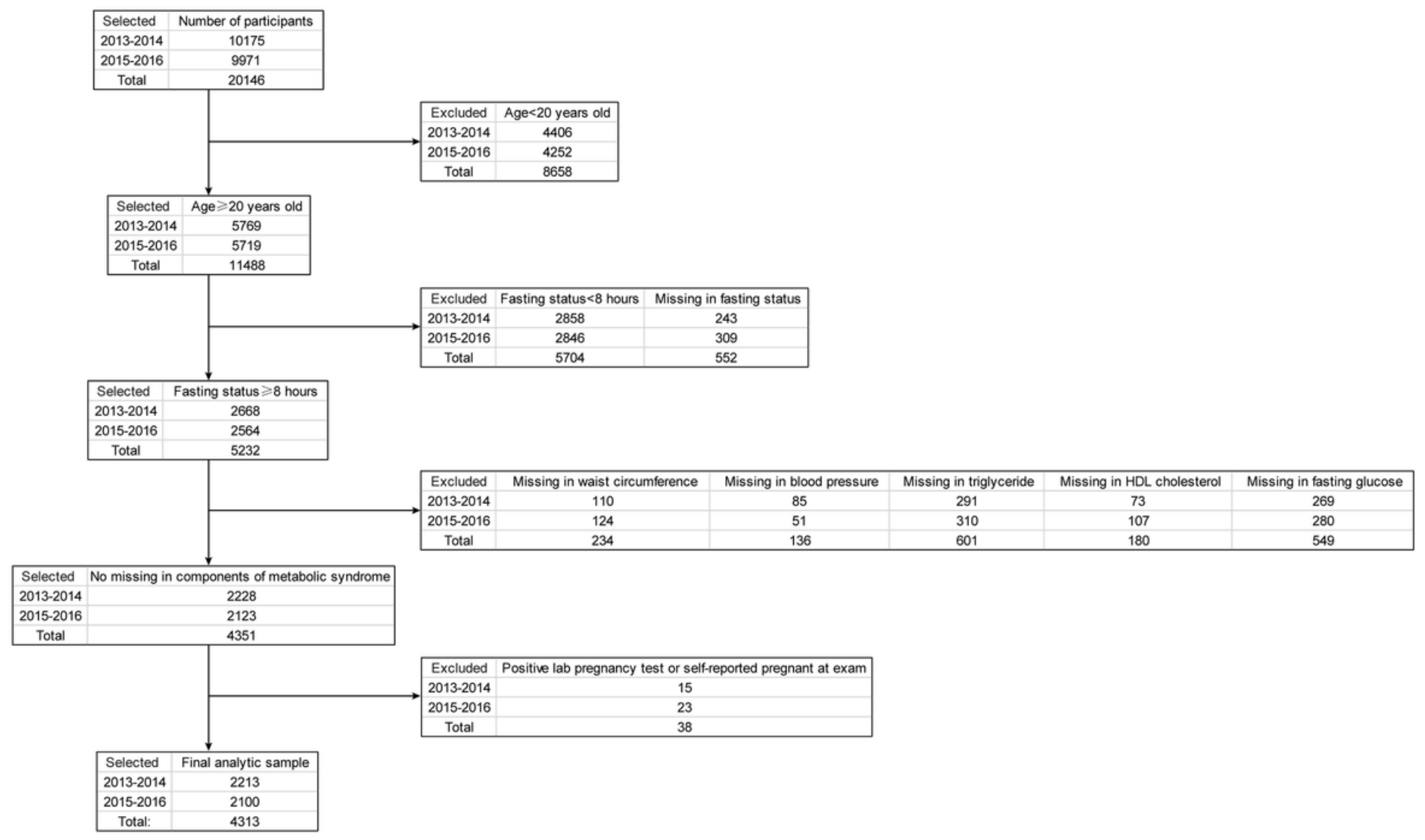

Figure 1

Flow chart of the study population selection. HDL: high-density lipoprotein.

\section{Supplementary Files}

This is a list of supplementary files associated with this preprint. Click to download.

- TableS11.docx

- Tables12.docx

- TableS13.docx

- TableS10.docx 